\title{
Spinal cord injuries in Japan: a nationwide epidemiological survey in 1990
}

\author{
H Shingu MD,${ }^{1} \mathrm{~T}$ Ikata MD ${ }^{2} \mathrm{~S}$ Katoh MD ${ }^{2} \mathrm{~T}$ Akatsu $\mathrm{MD}^{3}$
}

${ }^{1}$ President, Prevention Committee of the Japanese Medical Society of Paraplegia, Director of San-in Rosai Hospital, 1-8-1 Kaikeshinden Yonago 683; ${ }^{2}$ Department of Orthopaedic Surgery, Tokushima University School of Medicine, Tokushima 770; ${ }^{3}$ Spinal Injuries Centre, Iizuka 820, Japan.

To survey the situation of traumatic spinal cord injuries (SCI) in Japan, the SCI Prevention Committee of the Japanese Medical Society of Paraplegia sent out by mail study charts in the form of questionnaires to institutions nationwide. Using the statistical method of the nationwide epidemiological survey described by Hashimoto et al, ${ }^{1}$ the annual estimated incidence was obtained from the number of patients registered, and from the questionnaire reply rate at each prefecture. The number of registered patients in 1990 was 3465 and the mean reply rate was $56.6 \%$. There were 2665 registered patients with a neurological deficit (Frankel A-D) and the annual SCI incidence was 39.4 per million.

The male:female ratio was $4.3: 1$ and the ratio of cervical cord injures to those caudal to the cervical cord was 2.9:1. The mean age at the time of injury was 48.5 years. The cause most frequently seen was traffic accidents, the second most frequent being falls from a height. Besides those two, sports injuries and falls on level ground were the third most frequent causes of SCI in the young generation and in elderly people respectively.

Keywords: spinal cord injury; epidemiology; incidence; prevention; Japan.

\section{Introduction}

Since there is still a very long way to go to restore lost spinal cord function following spinal cord injury, prevention is better than treatment. Most spinal cord injuries (SCI) result from spinal trauma, some of which could have been prevented. In order to obtain basic data to organise a prevention campaign for SCI and spinal injuries, the Prevention Committee of the Japanese Medical Society of Paraplegia (JMSOP) conducted the first nationwide epidemiological survey in Japan.

\section{Materials and methods}

The SCI Prevention Programme Sub committee of JMSOP and regional supervisors of JMSOP mailed study charts in the form of questionnaires to all departments of orthopaedic, neurosurgery, rehabilitation and emergency medical service centres at nationwide institutions, which were as- sumed to accept SCI patients, and asked these institutions to return the filled-in questionnaire to the supervisor in each region. The institutions which had no spinal injury cases were also asked to reply. When institutions did not reply, a further request and confirmation by telephone was made for compiling of data.

In this study, patients were coded with the following numbers of the International Classification of Disease (1969): No. 806.0-9: fractures and fracture-dislocation of the vertebral column with SCI; and No. 952.0-9: SCI without evidence of spinal injury. Patients with paralysis and paresis as well as those suffering only from numbness without motor paralysis were included. Traumatic cervical syndrome cases (socalled distorted types of whiplash and autonomic imbalance) and the cases with extradural nerve root or plexus injury were excluded.

Using the statistical method of the nationwide epidemiological survey, ${ }^{1}$ the annual 
estimated incidence was obtained from the number of patients registered and from the questionnaire reply rate at each prefecture on a regional basis. Only those who were injured between 1st January and 31st December 1990 were accepted for the study. Those who came back to Japan after an injury abroad and also those who were treated only on an outpatient basis were excluded. The neurological deficits were classified using the Frankel classification. ${ }^{2}$

\section{Results}

The study charts in the form of a questionnaire were sent to 9270 departments at 8569 hospitals nationwide, of which 5247 replied. The mean reply rate was $56.6 \%$.

\section{Incidence}

A total of 3465 spinal injury patients in this year was registered (Table I). Excluding Frankel grade E, there were 2665 cases with Frankel grades A, B, C or D and the number estimated from the reply rate was 4876. As the population in Japan was $123,611,167$ in 1990 , the incidence of SCI was estimated from the number of patients registered and the reply rate was 39.4 per million per annum. The incidence of spinal injury patients including Frankel grade E was 50.5 per million per annum (Table II). The SCI patients with useless or worse motor function (Frankel grades A, B and C) accounted for about $60 \%$.

\section{Gender and age}

There were 2813 males and 651 females, besides one sex-unknown case. The number of males was 4.3 times as large as that of

Table I Neurological status of registered patients

\begin{tabular}{lrc}
\hline Frankel grade A & 921 & $(26.6 \%)$ \\
Frankel grade B & 433 & $(12.5 \%)$ \\
Frankel grade C & 692 & $(20.0 \%)$ \\
Frankel grade D & 619 & $(17.9 \%)$ \\
Frankel grade E & 792 & $(22.8 \%)$ \\
Unknown & 8 & $(0.2 \%)$ \\
Total & $3465(100 \%)$ \\
\hline
\end{tabular}

Table II Incidence of spinal cord injury estimated from the reply rate to the questionnaire; and the population of Japan in 1990

\begin{tabular}{lc}
\hline Population (million) & 123.611 \\
Number of departments & 9270 \\
Reply rate to questionnaire & $56.6 \%$ \\
Frankel grades A-D & \\
$\quad$ Registered number & 2665 \\
$\quad$ Estimated number & 4876 \\
Incidence (per million) & 39.4 \\
Frankel grades A-E & \\
$\quad$ Registered number & 3465 \\
Estimated number & 6239 \\
Incidence (per million) & 50.5 \\
\hline
\end{tabular}

females. The age at the time of injury varied from 6 to 92 years. The mean age with a standard deviation was $48.3 \pm 19.6$ years in the males, $49.2 \pm 19.3$ years in the females and $48.5 \pm 19.5$ years overall. The age distribution showed a diphasic feature, with a main peak in the age decade of 50 to 59 years and a small peak in the age decade of 20 to 29 years (Fig 1).

\section{Level of injury}

Of the registered 3465 cases, cervical cord injuries accounted for 2573 cases $(74.3 \%)$ and thoracic, lumbar and sacral cord as well as cauda equina injuries (caudal cervical cord injuries) amounted to 883 cases $(25.5 \%)$, with the incidence of the former being 2.9 times that of the latter. There were also nine cases $(0.2 \%)$ with unknown level injuries. The mean age at the time of injury was 50.8 years in the case of cervical cord injury and 39.7 years in the case of those caudal to the cervical cord. Comparison of the severity of neurological deficits revealed that complete injury accounted for

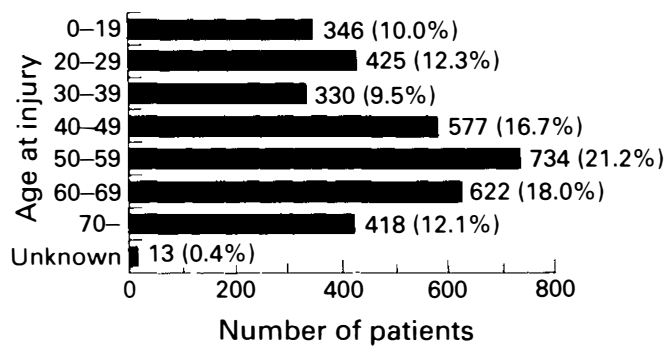

Figure 1 Age distribution at the time of injury. 
$21.9 \%$ of cervical cord injuries and for $40.3 \%$ of those caudal to the cervical cord.

\section{Causes of injuries}

The most frequent cause of the injury was traffic accidents (1547 cases, 44.6\%), followed by falls from a height (1012 cases, $29.2 \%$ ). Although there is some difficulty in distinguishing 'falls from a height' from 'falls on level ground', there were 407 cases $(11.8 \%)$ from falls on level ground including falls down a few stair steps. The three major causes of cervical cord injuries were traffic accidents, falls from a height and falls on level ground, while those below the cervical cord occurred mainly from falls from a height, traffic accidents and being struck by objects (Table III).

Regarding the age at the time of injury and the causes of the injuries: the mean age of those who had sports injuries was lowest at 26.1 years, those in traffic accident injuries and struck by objects were in their fifth decade, and those in falls from a height were in their sixth decade. The patients who were injured by falls on level ground were mostly elderly people (61.5 years old). Most with these types of falls sustained a cervical hyperextension injury. Traffic accidents and sports injuries were more frequent causes of injury among the young, while traffic accidents and falls from a height caused injuries in people of middle age and over. Most of the injuries in elderly people were caused by traffic accidents, falls from a height and falls on level ground (Table IV).

In the cases of injuries caused by traffic accidents, automobiles, motorbikes, bicycles and pedestrians were responsible respectively for $45.8 \%, 30.1 \%, 15.5 \%$ and $5.6 \%$ of these accidents. It was estimated that SCIs (2728 cases) occur approximately at the rate of $25 \%$ of the deaths $(11,227$ cases) by traffic accidents. Regarding the types of traffic accidents classified by age at

Table III Causes of injury, level of injury and age at the time of injury

\begin{tabular}{lcccrrr}
\hline Cause of injury & Cervical & $\begin{array}{c}\text { Below } \\
\text { cervical }\end{array}$ & Unknown & Total & $\begin{array}{c}\text { Age at } \\
\text { injury (yrs) }\end{array}$ \\
\hline Traffic accident & 1218 & 328 & 1 & 1547 & $(44.6 \%)$ & 44.1 \\
Fall from a height & 667 & 342 & 3 & 1012 & $(29.2 \%)$ & 52.8 \\
Fall on level ground & 356 & 48 & 3 & 407 & $(11.8 \%)$ & 61.5 \\
Being struck by object & 126 & 83 & & 209 & $(6.0 \%)$ & 47.8 \\
Sports & 158 & 24 & & 182 & $(5.3 \%)$ & 26.1 \\
Attempted suicide & 14 & 46 & & 60 & $(1.7 \%)$ & 31.3 \\
Others & 34 & 12 & 2 & 48 & $(1.4 \%)$ & 51.0 \\
Total & 2573 & 883 & 9 & $3465(100 \%)$ & 48.5 \\
\hline
\end{tabular}

Table IV Age distribution at the time of injury and the causes of SCI

\begin{tabular}{lrrrrrrrrr}
\hline Cause of injury & \multicolumn{10}{c}{ Age $(\mathrm{yrs})$} \\
\cline { 2 - 10 } & -19 & $20-29$ & $30-39$ & $40-49$ & $50-59$ & $60-69$ & $70+$ Unknown Total \\
\hline Traffic accident & 216 & 259 & 158 & 250 & 267 & 248 & 149 & 0 & 1547 \\
Fall from a height & 30 & 52 & 84 & 219 & 283 & 211 & 127 & 6 & 1012 \\
Fall on level ground & 6 & 14 & 14 & 34 & 93 & 117 & 129 & 0 & 407 \\
Being struck by object & 5 & 16 & 32 & 49 & 67 & 34 & 5 & 1 & 209 \\
Sports & 72 & 58 & 26 & 15 & 7 & 3 & 1 & 0 & 182 \\
Attempted suicide & 15 & 18 & 14 & 6 & 5 & 0 & 1 & 0 & 59 \\
Others & 2 & 8 & 2 & 4 & 12 & 9 & 6 & 6 & 49 \\
Total & 346 & 425 & 330 & 577 & 734 & 622 & 418 & 13 & 3465 \\
\hline
\end{tabular}


the time of injury, automobile accidents were noted to be a high percentage in each generation. Accidents related to motorbikes were also frequently encountered in the young, while elderly people were injured by automobiles. There were 673 cases of industrial injuries, accounting for $19.4 \%$ of all cases. The causes of SCIs were falls from a height $(50.2 \%)$, traffic accidents $(23.3 \%)$ including commuting accidents, and contusion due to being caught under heavy objects and wreckage (19.0\%). Of these 673 cases, cervical cord injuries accounted for $63.7 \%$, and those caudal to the cervical cord $36.3 \%$. There were 182 sports injuries, and the type of sport most frequently causing SCI was diving, followed by rugby, football, skiing, judo and wrestling, gymnastics and paragliding (Table V). In 19 cases the type of sport causing the injuries was not identified. A total of 44 people were injured by diving, and many had dived head first at a sharp angle into shallow water. These people usually sustained cervical cord injury, and a complete lesion occurred in $45.5 \%$. Twenty-one patients had dived into a swimming pool, $80 \%$ of these were under 19 years of age. A question asking whether the injury was influenced by drinking was included in the questionnaire. The percentages of those thought to be under the influence of alcohol were $32.3 \%$ of those in bicycle accidents, $27.8 \%$ of pedestrian victims of traffic accidents and $22.6 \%$ of those who fell on level ground, which compare with the rates of alcohol influence in other causes (Fig 2).

Table V Types of sports injury

\begin{tabular}{lr}
\hline Diving & 44 \\
Rugby & 24 \\
Skiing & 20 \\
Gymnastics & 14 \\
Judo, wrestling & 11 \\
Baseball & 11 \\
Gliding & 11 \\
Motocross & 5 \\
Others & 23 \\
Unknown & 19 \\
Total & 182 \\
\hline
\end{tabular}

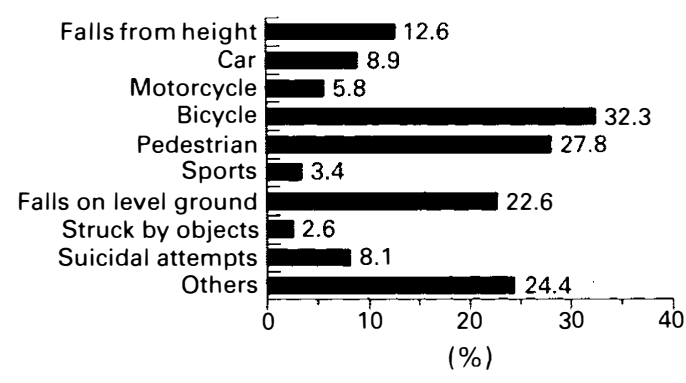

Figure 2 Ratios of SCI causes under influence of drinking alcohol.

\section{Discussion}

SCI results in a great loss for society as well as for the individuals themselves. Once a serious SCI occurs, the disability is very difficult to cure and gives rise to much human stress. We should make every effort to prevent SCI, as well as to improve the outcome of treatment for such injured patients. The campaign for prevention should be well organised, since the epidemiological data on SCI, which should be the basis of such a campaign, have not been available in Japan. JMSOP and The Western Japanese Research Society for the Spine started the epidemiological survey in the western part of Japan, using a postal questionnaire, in 1989. In the survey, 985 cases with Frankel A, B, C and D grades were registered, and these results encouraged us to extend the survey nationwide in 1990.

The incidence of SCI shows a discrepancy when comparing different reports. Reviewing the medical literature published from 1975 to 1990 , the incidence of the newly hospitalised patients was reported to range from 9.2 to 53.4 per million per annum. ${ }^{3-9}$ The difference of the socioeconomic situation in each region might be the leading cause of the discrepancy. The differences in the definition of SCI and of the epidemiological methods may, at least in part, contribute to the variation. ${ }^{10}$ The incidence in Japan was similar to that of recent studies in Australia, ${ }^{6}$ the Federal Republic of Germany ${ }^{7}$ and the USA, ${ }^{9}$ which were reported to range from 27.6 to 36.0 (Table VI).

One of the characteristic features of SCI in Japan was a higher age at the time of injury. Other reports showed the highest 
Table VI The incidence of spinal cord injury in the literature

\begin{tabular}{|c|c|c|c|c|c|}
\hline Authors & Region & Population (million) & Period & Number & Incidence \\
\hline Kraus $^{3}$ & Califorinia & 5.8 & $1970-1971$ & 619 & 53.4 \\
\hline $\begin{array}{l}\text { Biering- } \\
\quad \text { Sorensen }\end{array}$ & Denmark & 5.2 & $1975-1984$ & 268 & 9.2 \\
\hline $\mathrm{Chen}^{4}$ & Taipei & 2.1 & $1978-1981$ & 123 & 14.6 \\
\hline Walsh ${ }^{6}$ & Australia & 15.5 & 1980-1985 & 1915 & 27.6 \\
\hline Koning 7 & FRG & 61.5 & 1983 & 2213 & 36.0 \\
\hline DeLilla $^{9}$ & Florida & 11.9 & $1984-1988$ & 2138 & 36.0 \\
\hline This study & Japan & 123.6 & 1990 & 3465 & 39.4 \\
\hline
\end{tabular}

frequency in older adolescents and younger adults. ${ }^{4.5 .9}$ Although a small peak was seen in the third decade, the highest percentage was observed in the sixth decade, and the age group from 40 to 69 years comprised $55.8 \%$ in Japan. The high incidence of cervical cord injury $(74.3 \%)$ also differentiated this study from others. These features may partly reflect the high incidence of incomplete cervical cord injury in our aged population. The mean age of patients with injuries due to falls on level ground was 61.5 years and many of these falls caused a hyperextension neck injury. The increased incidence of the existence of ossification in the posterior longitudinal ligament, and the relatively narrow spinal canal may partly contribute to this fact.

Regarding the causes of SCI, road traffic accidents comprised the highest percentage. This finding is consistent with other reports. Motorcycle and car accidents were prominent in the younger population, while bicycle accidents were most prominent in the aged population. The high incidence of falls from a height and on level ground was another characteristic feature of SCI in Japan (Table VII). The rate of injuries due to falls from a height and on level ground almost reached that of injuries in road traffic accidents. The occurrence rate of SCI due to sports injury was lower than that reported from Australia and Florida. However, the growing enthusiasm in Japan for risky sports, such as rugby, football, skiing, motor racing, paragliding and hang gliding is likely to increase the occurrence of SCI. Stab and gunshot injuries rarely occur in Japan. With road traffic accidents on the way to work being classified as industrial accidents, $19.4 \%$ of all incidents were registered as industrial accidents. SCI due to industrial accidents has decreased in the last 20 years in spite of the increasing number of SCI caused by road traffic accidents.

On the basis of our estimate for Japan, every year nearly 5000 new SCI patients occur, and severely injured (Frankel grades $A$ and B) patients, whose functional recovery is unlikely, amounted to more than 2000. This study supports our clinical impression concerning the situation of SCI in

Table VII Causes of SCI in the cited literature

\begin{tabular}{lcccc}
\hline Cause of injury & Florida $^{9}$ & Australia $^{5}$ & Taipei $^{4}$ & Japan \\
\cline { 2 - 3 } Traffic accident & $45.1 \%$ & $58.0 \%$ & $44.5 \%$ & $44.7 \%$ \\
Fall & $17.1 \%$ & $18.1 \%$ & $28.0 \%$ & $40.9 \%$ \\
$\quad$ From a height & & & & $(29.2 \%)$ \\
$\quad$ On level ground & $8.5 \%$ & $11.7 \%)$ \\
Diving etc & $15.2 \%$ & $10.4 \%$ & $3.4 \%$ & $5.3 \%$ \\
Gunshot, stab & & $10.6 \%$ & $14.7 \%$ & $6.0 \%$ \\
Being struck by object & $14.1 \%$ & $2.9 \%$ & $6.8 \%$ & $3.1 \%$ \\
Others & & & \\
\hline
\end{tabular}


Japan and must be a good basis for the organisation of a campaign. According to the results of this study, the campaign should be focused mainly on the following topics: sports injury, especially diving accidents; motorcycle and car accidents involving adolescents and young adults; traffic accidents involving adults; falls; and bicycle accidents involving aged people. Each task is difficult to achieve. However, we should appeal to society to improve the circumstances which might lead to injury, as well as to the individuals themselves. Lastly, we are now carrying out a further epidemiological study.

\section{Acknowledgements}

The authors are grateful to Professor $\mathrm{T}$ Nose and Dr Y Kurosawa (Tottori University) for their assistance with the statistics and also to the doctors who registered the patients. The members of the SCI Prevention Programme Committee of JMSOP are as follows: $\mathrm{H}$ Abe, T Akatsu, Y Hatsuyama, T Ikata, E Iwatsubo, K Kaneda, S Katoh, T Koyanagi, K Ohotani, $\mathrm{H}$ Shingu, Y Takemitsu, K Yata. The members of the Subcommittee are as follows: $\mathrm{N}$ Andoh, M Ijichi, Y Iwasaki, J Kawamura, A Kurihara, M Murase, A Nagashima, R Nihei, Y Oda, T Oguma, M Ohhama, T Ohwada, T Satoh, K Shiba, K Shibasaki, S Tominaga, K Yoshinaga.

\section{References}

1 Hashimoto S, Fukutomi K, Nagai M, Nakamura Y, Yanagawa H, Sasaki R, Ohno Y, Aoki K (1991) Response bias in the nationwide epidemiological survey of an intractable disease in Japan. J Epidemiol 1: 27-30.

2 Frankel HL, Hancock DO, Hyslop G, Melzak J, Michaelis LS, Ungar GH et al (1969) The value of postural reduction in the initial management of closed injuries of the spine with paraplegia and tetraplegia. Paraplegia 7: 179-192.

3 Kraus JF, Franti CE, Riggins RS, Richards D, Borhani NO (1975) Incidence of traumatic spinal cord lesions. J Chron Dis 28: 471-492.

4 Chen CF, Lien IN (1985) Spinal cord injuries in Taipei, Taiwan, 1978-1981. Paraplegia 23: 364-370.

5 Burke DC, Toscano J (1987) Incidence and distribution of spinal cord injury. Menzies Foundation Technical Report 1: 13-47.

6 Walsh JE (1987) Actuarial research into physical disablement. Report of research project. 1: 1-114.

7 Koning W, Frowein RA (1989) Incidence of spinal cord injury in the Federal Republic of Germany. Neurosurg Rev 12: 562-566.

8 Biering-Sorensen F, Pedersen V, Clausen S (1990) Epidemiology of spinal cord lesions in Denmark. Paraplegia 28: 105-118.

9 DeLilla T, Eddy S, Cooper T, Hensley K (1990) Five year summary on spinal cord injury statistics, Florida. Private communication.

10 Kraus JF (1980) Injury to the head and spinal cord. The epidemiological relevance of the medical literature published from 1960 to 1978. J Neurosurg 53: S3-S10. 